\title{
Sensory Preferences for Fat and Sugar in Adolescence and Adult Life
}

\author{
ADAM DREWNOWSKI ${ }^{a}$ \\ Human Nutrition Program, School of Public Health \\ and \\ Department of Psychiatry, Medical School \\ University of Michigan \\ Ann Arbor, Michigan 48109
}

\section{INTRODUCTION}

It is widely accepted that children love sweets. ${ }^{1}$ The consumption of sugars is higher in childhood and adolescence than in adult life, and sugars contribute over one-quarter of all calories to the preadolescent diet. ${ }^{2,3}$ Sensory preferences for sweet taste are higher among children than among adults. Children and adolescents optimally prefer higher sucrose concentrations than do adults and often fail to show the standard sucrose breakpoint. ${ }^{4}$ Sweet taste preferences and sugar intakes, however, decline between childhood and adult life. Is there a link between sensory preferences and the patterns of food consumption?

There is much evidence that preferences for sweet taste are innate. Sucrose solutions are perceived as being pleasant from birth. Hedonic preferences for sweet taste, however, can be subject to modification early in life, and sensory preferences for sweet foods are often determined both by early exposure and the context in which sweetness is presented to the child. ${ }^{1,5}$

Studies of preschool children ${ }^{6}$ have shown that food preferences in early life are determined by two chief factors: familiarity and sweetness. In one study, 17 preschool children (3.7-4.7 years of age) were given a range of small, open-faced sandwiches on whole-wheat bread. The spreads used were margarine, margarine and mint jelly, peanut butter, peanut butter and grape jelly, cream cheese, cream cheese and honey, cream cheese and caviar, and cheddar cheese. The rank order of preference ratings showed good correlation with actual consumption of the sandwiches. The children best liked those foods that were both sweet and familiar to them. It is worth noting that the familiar, sweet foods were generally mixtures of sugar and fat.

The most familiar and preferred foods in early childhood tend to combine these two principal ingredients: sugar and fat. Fat and sugar are the chief components of peanut butter and jelly, chocolate candy, cookies, and ice cream. Data in TABLE 1 show the nutrient composition of different types of chocolate candy: it can be seen that sugar and fat account for up to $98 \%$ of total calories. The nutrient

a Address for correspondence: School of Public Health, University of Michigan, Ann Arbor, Michigan 48109. 
analysis of such foods as cookies or ice cream produces similar results: more than two-thirds of the calories are derived solely from sugar and fat. Sensory preferences for sweets reported by so many children and adolescents are likely to be preferences for these mixtures of sugar and fat. In terms of early exposure, it might even be argued that sugar is the principal vehicle for introducing fat into the children's diet. Indeed, several studies have linked the increasing prevalence of childhood obesity and associated diseases to elevated sugar and fat content of the typical American diet.

\section{SENSORY STUDIES}

Several laboratory studies ${ }^{1,7,8}$ have examined differences in preferences for sweet taste between children and adults. These (mostly cross-sectional) studies employed sucrose solutions in water as the chief sensory stimulus. The concentration of sucrose judged to be most pleasant was the principal dependent variable. Studies of 8-10-year-old children showed hedonic preference functions with

TABLE 1. Nutrient Composition of Selected Chocolates

\begin{tabular}{lccccc}
\hline & \multicolumn{3}{c}{$\begin{array}{c}\text { Kilocalories } \\
\text { (per package or bar) }\end{array}$} & \\
\cline { 2 - 4 } & Total & Sugar & Fat & & (S + F)/T \\
& & & \\
& & & \\
& 237 & 109 & 123 & \\
\hline M\&M/Mars Plain Chocolate Candies & 241 & 88 & 108 & 98 \\
M\&M/Mars Peanut Chocolate Candies & 274 & 116 & 117 & 81 \\
M\&M/Mars Snickers Bar & 226 & 80 & 126 & 85 \\
Hershey Milk Chocolate with Almonds Bar & 222 & 80 & 108 & 81 \\
Hershey Special Dark Chocolate Candy & 156 & 60 & 72 & 85 \\
Nestlé Crunch Bar &
\end{tabular}

${ }^{a}$ Kilocalories from sugar and fat as a percentage of total kilocalories.

no breakpoint: intensely sweet solutions (20\% sucrose) were liked the best. ${ }^{4}$ In contrast, studies with adults showed trends toward lower preferences for sweet taste, or negative correlations between age and the sugar level of the most preferred solutions. As noted by Beauchamp and Cowart, ${ }^{1}$ however, cross-sectional studies do not permit the attribution of changes in preference to aging itself. Prior exposure and consumption of sugar-rich foods must also be taken into consideration. In the only longitudinal study cited in the literature, ${ }^{1}$ Desor and Beauchamp evaluated 44 subjects who had been tested 9 years previously when they were 1115 years of age. The majority of subjects preferred a lower concentration on being retested. Sensory data suggest that there is a decline in preference for sweet taste between children and young adults.

What about sensory preferences for sugar and fat? Although milkshakes, ice cream, or chocolate candy have been used in studies with both children and adolescents, levels of sugar and fat have not been systematically varied in sensory evaluation studies. Only limited data are available on sensory preferences for sugar and fat in adolescence and adult life. 


\section{SUGAR AND FAT}

In a study conducted by Drewnowski and Greenwood, ${ }^{9}$ college-age men and women tasted chilled mixtures of milk, cream, and sugar. Twenty liquid stimuli incorporating five levels of fat (1-50\%, wt/wt) and four levels of sugar (0-20\%, $\mathrm{wt} / \mathrm{wt}$ ) were presented to subjects for sensory and hedonic evaluations. The subjects' estimates of stimulus sweetness, creaminess, and fat content rose as monotonic functions of sucrose and fat levels. In contrast, hedonic preference functions were strongly interactive, showing the presence of hedonic optima. The composition of the best-tasting mixture as determined with the help of a mathematical modeling technique known as the Response Surface Method was $9 \%$ sucrose and $20 \%$ fat.

In a follow-up study, ${ }^{10} 25$ subjects (average age: 20 years) evaluated the sweetness, fatness, and creaminess of liquid and solid dairy products containing between 1 and $50 \mathrm{~g}$ fat $/ 100 \mathrm{~g}$ and sweetened with $0-20 \%$ sucrose, wt/wt. Liquid foods included skim milk, milk, half and half, and heavy cream; solid foods ranged from low-fat cottage cheese to cream cheese spread "jelly roll" fashion on slices of white bread. The perception of fat content was greatly impaired in solid as opposed to liquid foods, as many subjects appeared unable to estimate the fat content of solid food samples. Despite impaired sensory perception, hedonic preference functions for liquid and solid food models shared many common features. Preferences for solid foods were strongly interactive and also varied with ingredient levels. The subjects reported maximal liking for solid mixtures containing $16 \%$ sugar and $35 \%$ fat. Additional consumption data indicate that sensory preference ratings were reliably linked to the number of jelly roll sandwiches subsequently consumed by the subjects in the laboratory.

Further studies conducted with cake frostings-combinations of powdered sugar and butter-indicate that hedonic ratings are strongly context specific. Cake frostings are said to be irresistible to children, but many adults find them too rich and intensely sweet. Typical commercial cake icings contain over $70 \%$ sugar and $15-20 \%$ fat. Fifty college women were asked to taste a range of butterfat icings as well as sucrose solutions of different concentrations, all of these foods being presented at room temperature for sensory and hedonic evaluations. The subjects (average age: 22 years) showed a mild dislike for sucrose solutions in water, and the group breakpoint for sweetness was $8 \%$ sucrose in water. The same group, however, showed the highest preferences for icings containing between 60 and $70 \%$ sucrose and up to $25 \%$ butter. Sensory preferences for sweetness depend on the nature of the stimulus, and are clearly modified by the presence of other ingredients, including fat.

\section{FOOD PREFERENCES}

Surveys of adolescent food habits are typically based on food check lists and thus reflect attitudes toward specific foods rather than accurate patterns of food intake. ${ }^{11,12}$ In general, adolescents report liking such foods as hamburgers; steaks or chicken; sweet foods including cakes, pies, and soft drinks; as well as French fried potatoes. Young army recruits expressed preferences for steaks, corn on the cob, orange juice, milk, beer, and strong dislikes for "diet-type" foods, including fruit yogurt, diet soda, and skim milk. In a Canadian study, ${ }^{13}$ teenage boys reported more frequent intake of foods higher in fat, sugar, and salt, whereas young 
girls alleged they consumed more salads and vegetables. Self-reports of food preferences are clearly influenced by sex roles and attitudes toward body weight and dieting, and may not provide an accurate measure of food consumption.

\section{CONSUMPTION MEASURES}

What are the chief sources of sugar consumed by children, adolescents, and adults? How much sugar or fat do children and adults actually consume? For small population samples, it is feasible to employ trained observers to document the food habits of children, as was done in a recent study. ${ }^{14}$ Enumeration of the foods consumed over 3 days by schoolchildren in Washington, DC is provided in TABLE 2: it can be seen that the most frequently consumed foods include candy, other sweets, potato chips, and carbonated beverages. Measures of the frequency of food intake, however, seldom provide information regarding the amounts con-

TABLE 2. Food Preferences in Adolescents ${ }^{a}$

\begin{tabular}{clc}
\hline Rank & \multicolumn{1}{c}{ Food ${ }^{b}$} & $\begin{array}{c}\text { Number of } \\
\text { Times Eaten }\end{array}$ \\
\hline 1 & Candy & 240 \\
2 & Potato chips, popcorn & 198 \\
3 & Sweetened Kool-Aid drink & 146 \\
4 & Dry presweetened cereal & 119 \\
5 & Carbonated beverages & 128 \\
6 & Cupcakes, doughnuts, pies & 102 \\
7 & Milk & 98 \\
8 & Hamburger & 85 \\
9 & Spaghetti, macaroni & 85 \\
10 & Fried chicken & 82 \\
11 & Hot dog & 76 \\
12 & Bread & 75 \\
\hline
\end{tabular}

" Adapted from Davidson et al. ${ }^{14}$

b The foods listed are those most frequently consumed by schoolchildren (3-day observations).

sumed. Questions regarding caloric intakes can be answered by examining individual records of food intake for large population samples, stratified by both sex and age.

Studies based on 7-day food diaries of a cross-sectional sample of 657 American children 5-12 years of age show that the average daily consumption of sugars was $134 \mathrm{~g} /$ day (TABLE 3 ). The chief source of sugars was lactose in milk (26 g/ day). Other contributing food groups were cakes, cookies, pies, and desserts (15 $\mathrm{g} /$ day); sweetened beverages (18 $\mathrm{g} /$ day); fruit and fruit juices ( $25 \mathrm{~g} /$ day); and candy and ice cream ( $11 \mathrm{~g} /$ day). In many of these foods (for example, milk), sugar, whether natural or added, was presented in combination with dietary fat.

The Nationwide Food Consumption Survey examines household food use and individual food intakes for even larger samples of the U.S. population. Last conducted in 1977-1978 by the U.S. Department of Agriculture, the Nationwide Food Consumption Survey compiled 3-day records of foods used in 15,000 house- 
TABLE 3. Average Daily Intake of Sugar ${ }^{a}$

\begin{tabular}{lcc}
\hline \multicolumn{1}{c}{ Food Group } & $\begin{array}{c}\text { Average } \\
\text { Sugar Intake } \\
(\mathrm{g})\end{array}$ & $\begin{array}{c}\text { Percentage } \\
\text { of Total } \\
\text { Sugar Intake }\end{array}$ \\
\hline Breakfast cereals & 4.2 & 3.3 \\
Cakes, cookies, pies & 15.3 & 11.2 \\
Candy & 3.7 & 2.6 \\
Breads, donuts, rolls & 7.4 & 5.7 \\
Fruit & 17.1 & 11.5 \\
Fruit juices & 12.0 & 8.8 \\
Jellies, sauces, syrups, and table sugar & 17.3 & 12.3 \\
Milk & 25.9 & 20.4 \\
Sweetened beverages & 17.9 & 13.8 \\
Sweet dairy products & 7.4 & 5.5 \\
Other foods & 6.1 & 4.9 \\
All foods (total) & 134.3 & 100.0 \\
\hline
\end{tabular}

"The data in this table are from 7-day observations of 5-12-year-old children $(N=657)$. Adapted from Morgan and Zabik. ${ }^{3}$

holds. Individual respondents recalled the food intake for the first day of the survey and kept a diary for 2 additional days. According to survey estimates, fat was responsible for $41 \%$ and carbohydrate for $43 \%$ of food calories in the U.S. diet.

Mean daily intake of sugars is known to vary for different population groups. The reported daily intakes of sugars, carbohydrate, and calories are presented in TABLE 4. The intake of added sugars for the different population subgroups ranged between 35 and $84 \mathrm{~g} /$ day, with a mean of $53 \mathrm{~g} /$ day for the total population. The intake of naturally occurring sugars (mostly lactose from milk) ranged be-

TABLE 4. Average Daily Intake of Sugars, Carbohydrate, and Calories ${ }^{a}$

\begin{tabular}{|c|c|c|c|c|c|}
\hline \multirow[b]{2}{*}{$\begin{array}{c}\text { Age } \\
\text { (years) }\end{array}$} & \multicolumn{3}{|c|}{$\begin{array}{c}\text { Average Intake } \\
\text { (g/day) }\end{array}$} & \multirow[b]{2}{*}{$\underset{\text { (g/day) }}{\mathrm{CHO}}$} & \multirow[b]{2}{*}{$\begin{array}{l}\text { Calories } \\
\text { per Day }\end{array}$} \\
\hline & $\begin{array}{l}\text { Added } \\
\text { Sugars }\end{array}$ & $\begin{array}{c}\text { Natural } \\
\text { Sugars }\end{array}$ & $\begin{array}{l}\text { Total } \\
\text { Sugars }\end{array}$ & & \\
\hline \multicolumn{6}{|l|}{ Males } \\
\hline $11-14$ & 76 & 57 & 133 & 257 & 2252 \\
\hline $15-18$ & 84 & 59 & 143 & 283 & 2578 \\
\hline $19-22$ & 73 & 47 & 121 & 248 & 2403 \\
\hline $23-50$ & 62 & 43 & 105 & 230 & 2330 \\
\hline$>50$ & 48 & 45 & 92 & 206 & 2042 \\
\hline \multicolumn{6}{|l|}{ Females } \\
\hline $11-14$ & 65 & 47 & 112 & 214 & 1856 \\
\hline $15-18$ & 62 & 41 & 103 & 196 & 1746 \\
\hline $19-22$ & 52 & 34 & 86 & 170 & 1600 \\
\hline $23-50$ & 44 & 33 & 78 & 158 & 1548 \\
\hline$>50$ & 35 & 38 & 74 & 155 & 1470 \\
\hline
\end{tabular}

" Data from the Nationwide Food Consumption Survey, 1977-1978. 
tween 33 and $59 \mathrm{~g} /$ day (mean: $42 \mathrm{~g} /$ day). The total intake ranged between 74 and $143 \mathrm{~g} /$ day (mean: $95 \mathrm{~g} /$ day).

The same data, expressed as percentages of the total daily intake in calories, are shown in TABLE 5. It can be seen that the highest percentage of total calories derived from sugars $(22-24 \%)$ is observed for the two youngest age groups: children and teenagers. There has been some concern that these groups are most susceptible to the adverse health effects of excessive sugar consumption. Several investigators have suggested that the addition of refined sugars to the children's diet is directly linked to the development of childhood and juvenile onset obesity. ${ }^{2}$

The nutrient composition of foods reported to be highly preferred by children deserves further examination. The Nutrient Data Bank provides a list of over 60 nutrients for a large portion of some $10,000-15,000$ foods in the U.S. food supply. This list is updated on a continuing basis by the U.S. Department of Agriculture Nutrient Composition Lab (Beltsville), and is the source for the U.S. Department

TABLE 5. Average Daily Intake of Sugars and Carbohydrate as a Percentage of Calories

\begin{tabular}{|c|c|c|c|c|}
\hline \multirow[b]{2}{*}{$\begin{array}{c}\text { Age } \\
\text { (years) }\end{array}$} & \multicolumn{3}{|c|}{$\begin{array}{c}\text { Average Daily Intake } \\
(\%)\end{array}$} & \multirow[b]{2}{*}{$\begin{array}{c}\text { Carbohydrate } \\
(\%)\end{array}$} \\
\hline & $\begin{array}{l}\text { Added } \\
\text { Sugars }\end{array}$ & $\begin{array}{l}\text { Natural } \\
\text { Sugars }\end{array}$ & $\begin{array}{l}\text { Total } \\
\text { Sugars }\end{array}$ & \\
\hline \multicolumn{5}{|l|}{ Males } \\
\hline $11-14$ & 13 & 10 & 23 & 46 \\
\hline $15-18$ & 13 & 9 & 22 & 44 \\
\hline $19-22$ & 12 & 8 & 20 & 42 \\
\hline $23-50$ & 11 & 7 & 18 & 39 \\
\hline$>50$ & 9 & 9 & 18 & 41 \\
\hline \multicolumn{5}{|l|}{ Females } \\
\hline $11-14$ & 14 & 10 & 24 & 46 \\
\hline $15-18$ & 14 & 9 & 24 & 45 \\
\hline $19-22$ & 13 & 9 & 22 & 43 \\
\hline $23-50$ & 11 & 9 & 20 & 41 \\
\hline$>50$ & 9 & 11 & 20 & 42 \\
\hline
\end{tabular}

${ }^{a}$ Data from the Nationwide Food Consumption Survey, 1977-1978.

of Agriculture Handbook No. 8. Other nutrient databases, including the Michigan State University Nutrient Data Bank, list sugar content for a large number of brand-name foods, including sweets, candy, and other desserts.

Data from the Second National Health and Nutrition Examination Survey show that the chief sources of dietary carbohydrate in the U.S. diet include bread, soft drinks, doughnuts, cookies, milk, fried potatoes, alcohol, and orange juice. Many of these products contain added sugar: soft drinks, pastries, and sugar together contribute almost $20 \%$ of the total carbohydrate intake. Among other products containing appreciable amounts of added sugar are milk beverages, yogurts, ice cream, puddings and other milk desserts, muffins, biscuits, doughnuts, cakes, cookies, pies, cereals, syrups, dessert toppings, jams, preserves, gelatin desserts, popsicles, candies, and chewing gums. ${ }^{15.16}$ 


\section{CONCLUSION}

The observed decline in sensory preferences for sweetness is paralleled by a decline in the consumption of naturally occurring and added sugars between adolescence and adult life. This is especially striking when presented in terms of grams of sugar consumed per day per kilogram of body weight, as shown in TABLE 6. Sensory and intake data suggest that this decline is more pronounced among women than among men. It is unclear to what extent attitudinal factors, including concern with body weight and dieting, influence hedonic preferences for sweet calorie-dense foods.

In contrast to the intake of sugars, the consumption of fats increases between childhood and adult life. Children under 9 years of age show the lowest fat in-

TABLE 6. Average Daily Intake of Sugars on a Body Weight Basis

\begin{tabular}{cccc} 
& \multicolumn{3}{c}{$\begin{array}{c}\text { Average Daily Intake } \\
\text { (g/kg body weight/day) }\end{array}$} \\
\cline { 2 - 5 } $\begin{array}{c}\text { Age } \\
\text { (years) }\end{array}$ & $\begin{array}{c}\text { Added } \\
\text { Sugar }\end{array}$ & $\begin{array}{c}\text { Total } \\
\text { Sugar }\end{array}$ & $\begin{array}{c}\text { Total Minus } \\
\text { Lactose }\end{array}$ \\
\hline Both sexes & & & \\
$<1$ & 1.3 & 8.5 & 3.9 \\
$1-3$ & 2.9 & 6.1 & 4.6 \\
$4-6$ & 2.8 & 5.1 & 4.0 \\
$7-10$ & 2.2 & 4.0 & 3.1 \\
Males & & & \\
$11-14$ & 1.7 & 2.9 & 2.3 \\
$15-18$ & 1.3 & 2.2 & 1.8 \\
$19-22$ & 1.0 & 1.7 & 1.4 \\
$23-50$ & 0.8 & 1.3 & 1.2 \\
$>50$ & 0.6 & 1.2 & 1.1 \\
Females & & & \\
$11-14$ & 1.5 & 2.5 & 2.1 \\
$15-18$ & 1.2 & 1.9 & 1.6 \\
$19-22$ & 0.9 & 1.5 & 1.3 \\
$23-50$ & 0.7 & 1.3 & 1.1 \\
$>50$ & 0.6 & 1.2 & 1.0 \\
\hline
\end{tabular}

a Data from the Nationwide Food Consumption Survey, 1977-1978.

takes, whereas adults consume between 60 and $100 \mathrm{~g} /$ day. It should be noted that the extent of human ability to accurately assess the fat content of foods may be limited. Many nutritionists regard fat as "hidden calories" because consumers are often unaware of the fat content of common foods. With the current health emphasis on low-fat diets and the development of fat substitutes, there is a need for basic research on sensory and hedonic aspects of fats and the nature of human preferences for fat-containing foods.

\section{REFERENCES}

1. Beauchamp, G. K. \& B. J. Cowart. 1986. Development of sweet taste. In Sweetness. J. Dobbing, Ed.: 126-140. Springer-Verlag, New York, NY.

2. Glinsman, W. H., H. Irausquin \& Y. K. Park. 1986. Evaluation of health aspects of 
sugars contained in carbohydrate sweeteners: Report of the Sugars Task Force. J. Nutr. 116(11S): S1-S216.

3. Morgan, K. J. \& M. E. ZABik. 1981. Amount and food sources of total sugar intake by children aged 5 to 12 years. Am. J. Clin. Nutr. 34: 404-413.

4. Grinker, J. A., J. M. Price \& M. R. C. Greenwood. 1976. Studies of taste in childhood obesity. In Hunger: Basic Mechanisms and Clinical Implications. D. Novin, W. Wyrwicka \& G. A. Bray, Eds.: 441-457. Raven Press, New York, NY.

5. Beauchamp, G. K. \& M. Moran. 1984. Acceptance of sweet and salty tastes in 2year-old children. Appetite 5: 291-305.

6. BIRCH, L. L. 1979. Preschool children's food preferences and consumption patterns. J. Nutr. Educ. 11: 189-192.

7. Desor, J. A., L. S. Green \& O. Maller. 1975. Preferences for sweet and salty in 9-15-year-old and adult humans. Science 190: 686-687.

8. Enns, M. P., T. B. Van Itallie \& J. A. Grinker. 1979. Contributions of age, sex and degree of fatness on preferences and magnitude estimations for sucrose in humans. Physiol. Behav. 22: 999-1003.

9. Drewnowski, A. \& M. R. C. Greenwood. 1983. Cream and sugar: Human preferences for high-fat foods. Physiol. Behav. 30: 629-633.

10. Drewnowski, A., E. E. Shrager, C. Lipsky, E. Stellar \& M. R. C. Greenwood. Sugar and fat: Sensory and hedonic evaluation of liquid and solid foods. Physiol. Behav. 45: 177-183.

11. Logue, A. W. \& M. E. SMith. 1986. Predictors of food preferences in adult humans. Appetite 7: 109-125.

12. PILgrim, F. 1961. What foods do people accept or reject? J. Am. Diet. Assoc. 38: 439 443.

13. George, R. S. \& M. Krondl. 1983. Perceptions and food use of adolescent boys and girls. Nutr. Behav. 1: 115-125.

14. Davidson, F. R., L. A. Hayek \& A. M. Altschul. 1986. Toward accurate assessment of children's food consumption. Ecol. Food Nutr. 18: 309-317.

15. Marston, R. M. \& N. R. Raper. 1985. The nutrient content of the food supply. Natl. Food. Rev. 29: 5-7.

16. Block, G., C. M. Dresser, A. M. Hartman \& M. D. Carroll. 1985. Nutrient sources in the American diet: Quantitative data from the NHANES II survey. Am. J. Epidemiol. 122: 27-40. 